\title{
Biocompatible Bacterial Cellulose-Poly(2-hydroxyethyl methacrylate) Nanocomposite Films
}

\author{
Andrea G. P. R. Figueiredo, ${ }^{1}$ Ana R. P. Figueiredo, ${ }^{1}$ Ana Alonso-Varona, ${ }^{2}$ \\ Susana C. M. Fernandes, ${ }^{1,3}$ Teodoro Palomares, ${ }^{2}$ Eva Rubio-Azpeitia, ${ }^{2}$ \\ Ana Barros-Timmons, ${ }^{1}$ Armando J. D. Silvestre, ${ }^{1}$ Carlos Pascoal Neto, ${ }^{1}$ \\ and Carmen S. R. Freire ${ }^{1}$ \\ ${ }^{1}$ Department of Chemistry and CICECO, Campus de Santiago, University of Aveiro, 3810-193 Aveiro, Portugal \\ ${ }^{2}$ Department of Cellular Biology and Histology, Faculty of Medicine and Odontology, University of the Basque Country (UPV/EHU), \\ Barrio Sarriena s/n, 48940 Leioa, Spain \\ 3 "Materials + Technologies" Group, Department of Chemical and Environmental Engineering, Polytechnic School, University of the \\ Basque Country (UPV/EHU), Plaza Europa 1, 20018 San Sebastián, Spain
}

Correspondence should be addressed to Carmen S. R. Freire; cfreire@ua.pt

Received 30 April 2013; Accepted 15 July 2013

Academic Editor: Dong-Wook Han

Copyright (C) 2013 Andrea G. P. R. Figueiredo et al. This is an open access article distributed under the Creative Commons Attribution License, which permits unrestricted use, distribution, and reproduction in any medium, provided the original work is properly cited.

\begin{abstract}
A series of bacterial cellulose-poly(2-hydroxyethyl methacrylate) nanocomposite films was prepared by in situ radical polymerization of 2-hydroxyethyl methacrylate (HEMA), using variable amounts of poly(ethylene glycol) diacrylate (PEGDA) as crosslinker. Thin films were obtained, and their physical, chemical, thermal, and mechanical properties were evaluated. The films showed improved translucency compared to $\mathrm{BC}$ and enhanced thermal stability and mechanical performance when compared to poly(2hydroxyethyl methacrylate) (PHEMA). Finally, BC/PHEMA nanocomposites proved to be nontoxic to human adipose-derived mesenchymal stem cells (ADSCs) and thus are pointed as potential dry dressings for biomedical applications.
\end{abstract}

\section{Introduction}

Cellulose, the most abundant natural polymer, possesses unique properties and advantages [1-4], which have been widely explored for centuries, especially for paper making and for textile materials. More recently, cellulose fibres have also gained considerable and increasing attention as reinforcing elements in polymeric (nano)composite materials $[1,5-7]$. Bacterial cellulose (BC) is a unique form of cellulose, produced by several bacteria of the Gluconacetobacter and Sarcina genus, among others $[8,9]$. Because of its inherent biocompatibility and unique properties, that arise from the tridimensional network of nano- and microfibrils, bacterial cellulose is becoming a promising biopolymer for several biomedical [6, 10-16] (e.g., wound dressing, artificial skin, and scaffolds for tissue engineering and soft tissue replacement) and technological [17-21] applications (e.g., optical transparent nanocomposites, electronic paper, and fuel cell membranes). $\mathrm{BC} /$ polymer nanocomposites have been prepared by simple blending of $\mathrm{BC}$ nanofibrils with several polymeric matrices [22-27] or by in situ polymerization of monomers within the cellulose network [16, 28-32]. The latter approach is particularly straightforward because the properties of the nanocomposites can be easily tailored by adjusting the ratio of monomer/BC, the type and functionalities of the monomers, degree of cross-linking, and so forth. A limited number of monomers with acrylic/methacrylic moieties, such as glycerol monomethacrylate (GMMA) [16], 2-hydroxyethyl methacrylate (HEMA) [16, 31], 2-ethoxyethyl methacrylate (EOEMA) [16], acrylamide [28, 30], acrylic acid 


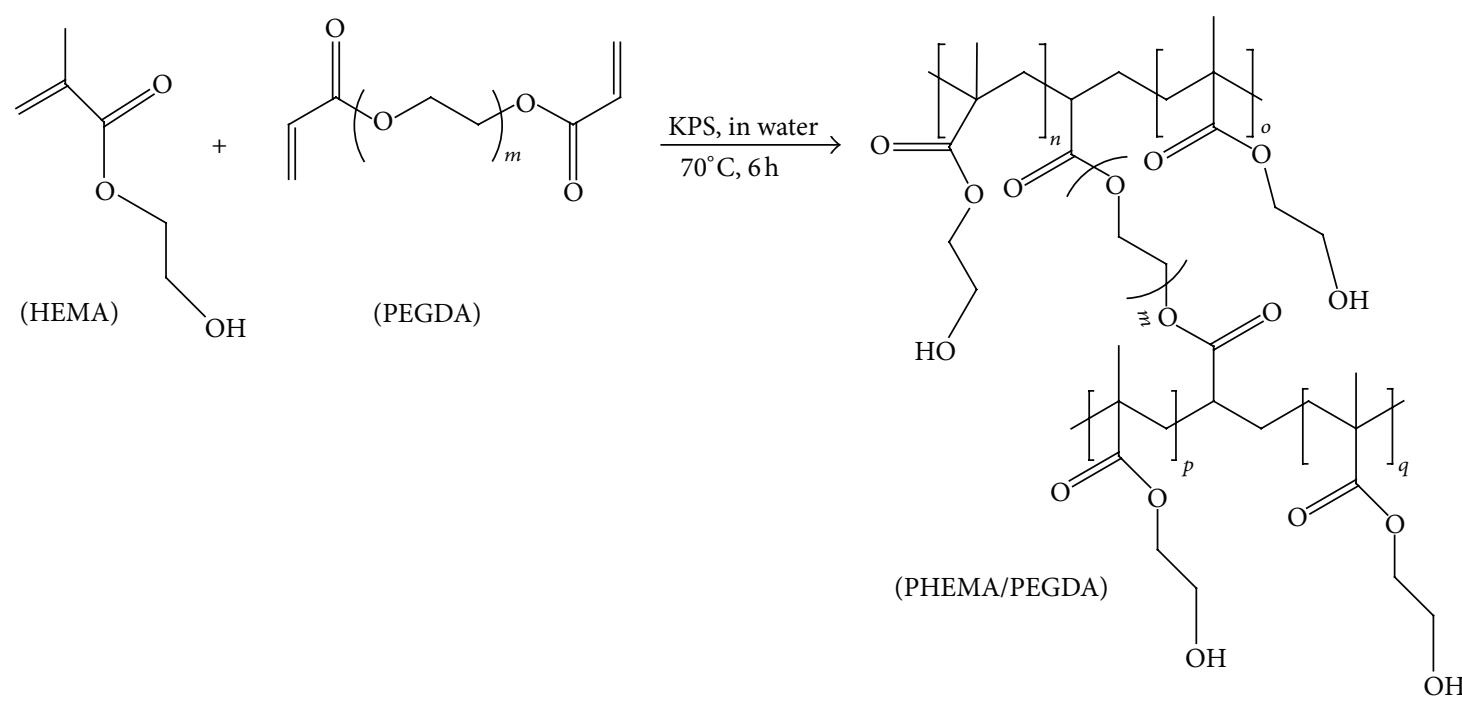

FIGURE 1: Schematic representation of HEMA polymerization, in the presence of PEGDA, to yield PHEMA cross-linked with PEGDA.

[29, 31, 32], and 2-ethylhexyl acrylate [31], have already been explored in this context, in particular for the development of $\mathrm{BC} /$ based hydrogels.

Poly(2-hydroxyethyl methacrylate) (PHEMA) is a versatile synthetic polymer with properties suited to a range of applications, in particular biomedical applications, including soft contact lenses [33], artificial corneas [34], degradable scaffolds for tissue engineering [35], and drug delivery systems [36]. BC/PHEMA hydrogels have already been described as part of two studies dealing with the preparation of $\mathrm{BC}$ based hydrogels by in situ polymerization of several acrylic monomers. In both cases the authors focus essentially on the swelling behaviour, morphology, and mechanical properties of the hydrogels. Other important properties, such as thermal stability, transparency, crystallinity, and biocompatibility, as well as their preparation in other forms such as films or aerogels, were not investigated and are also important for several applications.

In the present study, BC/PHEMA nanocomposites in the form of thin films were prepared by in situ radical polymerization in the presence of poly(ethylene glycol) diacrylate (PEGDA) as cross-linker (Figure 1). The effect of the content of monomer and cross-linker was evaluated. The ensuing nanocomposites were characterized in terms of chemical structure, crystallinity, transparency, morphology, thermal stability, mechanical properties, and biocompatibility.

\section{Materials and Methods}

2.1. Chemicals and Materials. 2-Hydroxyethyl methacrylate ((HEMA) 97\%, stabilized) and poly(ethylene glycol) diacrylate ((PEGDA) average Mn 258, stabilized) were purchased from Sigma-Aldrich and used as received. Potassium persulfate ((KPS) 98\%, Panreac) was used as thermal initiator. All other reagents and solvents were of analytical grade and used as received.
Bacterial cellulose (BC) (tridimensional network of nanoand microfibrils with $10-200 \mathrm{~nm}$ width) in the form of wet membranes was produced in our laboratory using the Gluconacetobacter sacchari bacterial strain [8] and following established procedures [37].

2.2. BC/PHEMA Nanocomposites Preparation. Wet BC membranes ( $\sim 100 \mathrm{mg}$ dry weigh, $4 \times 4 \mathrm{~cm}^{2}$, and $0.8 \mathrm{~cm}$ thickness) were weighted, and $60 \%$ of their water content was removed with absorbent paper. Drained BC membranes were put in Erlenmeyers stopped with rubber septa and then purged with nitrogen. At the same time, aqueous solutions $(5 \mathrm{~mL})$ with different amounts of monomer HEMA $(75 ; 150 ; 300 \mathrm{mg}), 1.2 \%$ of KPS inititaor ( $w / w$ relative to monomer), and PEGDA (0, 1 , and $\left.5 \%\left(\mathrm{w}_{\text {cross-linker }} / \mathrm{w}_{\text {monomer }}\right)\right)$ were prepared (Table 1$)$ and also purged with nitrogen (in an ice bath) for $30 \mathrm{~min}$. Then, the solutions were transferred with a syringe to the Erlenmeyers containing the drained $\mathrm{BC}$ membranes. After that, the membranes were left to stand for 1 hour at room temperature $\left(25^{\circ} \mathrm{C}\right)$ until the complete absorption/incorporation of the solutions. Subsequently, the reaction mixtures were left at $70^{\circ} \mathrm{C}$ (to induce in situ radical polymerization), for $6 \mathrm{~h}$. Then, the septum was pulled off and the BC membranes washed with water $(100 \mathrm{~mL})$ during $30 \mathrm{~min}$. This washing procedure was repeated three times. The washed membranes were placed over Petri dishes and dried at $40^{\circ} \mathrm{C}$ in a ventilated oven for 5-12 h. The dried membranes were kept in a desiccator until their use. All experiments were made in triplicate and analysed in the form of thin nanocomposite films. Samples of PHEMA and PHEMA cross-linked with PEGDA were prepared under the same conditions, in the absence of $\mathrm{BC}$ for comparative purposes.

Three samples from each series were freeze-dried and weighed. PHEMA/PEGDA and BC percent composition of the nanocomposites (Table 1) were estimated by difference to the original $\mathrm{BC}$ weight. 
TABLE 1: Identification of the nanocomposite films and component contents estimation.

\begin{tabular}{|c|c|c|c|c|c|}
\hline $\begin{array}{l}\text { BC/PHEMA/PEGDA } \\
\text { nanocomposites }\end{array}$ & Dry BC (mg) & HEMA (mg) & PEGDA (\%) & PHEMA (\%) & $\mathrm{BC}(\%)$ \\
\hline $\begin{array}{l}\text { BC/PHEMA/PEGDA } \\
(1: 3: 0)\end{array}$ & & & 0 & 74.0 & 26.0 \\
\hline $\begin{array}{l}\text { BC/PHEMA/PEGDA } \\
(1: 3: 0.01)\end{array}$ & 100 & 300 & 1 & 73.9 & 26.1 \\
\hline $\begin{array}{l}\text { BC/PHEMA/PEGDA } \\
(1: 3: 0.05)\end{array}$ & & & 5 & 75.9 & 24.1 \\
\hline $\begin{array}{l}\text { BC/PHEMA/PEGDA } \\
(1: 1.5: 0)\end{array}$ & & & 0 & 57.0 & 43.0 \\
\hline $\begin{array}{l}\text { BC/PHEMA/PEGDA } \\
(1: 1.5: 0.01)\end{array}$ & 100 & 150 & 1 & 59.2 & 40.8 \\
\hline $\begin{array}{l}\text { BC/PHEMA/PEGDA } \\
(1: 1.5: 0.05)\end{array}$ & & & 5 & 61.0 & 39.0 \\
\hline $\begin{array}{l}\text { BC/PHEMA/PEGDA } \\
(1: 0.75: 0)\end{array}$ & & & 0 & 36.1 & 63.9 \\
\hline $\begin{array}{l}\text { BC/PHEMA/PEGDA } \\
(1: 0.75: 0.01)\end{array}$ & 100 & 75 & 1 & 40.3 & 59.7 \\
\hline $\begin{array}{l}\text { BC/PHEMA/PEGDA } \\
(1: 0.75: 0.05)\end{array}$ & & & 5 & 44.8 & 55.2 \\
\hline
\end{tabular}

2.3. Nanocomposite Films Characterization. All ensuing films were characterized in terms of structure (FTIR and $\left.{ }^{13} \mathrm{C} \mathrm{NMR}\right)$, morphology (SEM), crystallinity (XRD), transparency/opacity (visible light), thermal stability and degradation profile (TGA), thermodynamical properties (DMA), swelling behaviour, and biocompatibility.

FTIR spectra were taken with a Perkin-Elmer FT-IR System Spectrum BX spectrophotometer equipped with a single horizontal Golden Gate ATR cell over the range 600$4000 \mathrm{~cm}^{-1}$ at a resolution of $4 \mathrm{~cm}^{-1}$ averaged over 32 scans.

CPMAS ${ }^{13} \mathrm{C}$ NMR spectra were recorded on a Bruker Avance III 400 spectrometer operating at a B0 field of $9.4 \mathrm{~T}$ using $9 \mathrm{kHz}$ MAS with proton $90^{\circ}$ pulse of $3 \mu \mathrm{s}$. CPMAS ${ }^{13} \mathrm{C}$ NMR spectra were acquired using a contact time of $2000 \mathrm{~ms}$ and a time between scans of $3 \mathrm{~s} .{ }^{13} \mathrm{C}$ chemical shifts were referenced with respect to glycine ( $\mathrm{C}=\mathrm{O}$ at $176.03 \mathrm{ppm})$.

SEM micrographs of the nanocomposite film surfaces were obtained on an HR-FESEM SU-70 Hitachi equipment operating at $1.5 \mathrm{kV}$ and that of BC was taken with a Hitachi S4100 equipment operating in the field emission mode. Samples were deposited on a steel plate and coated with carbon.

The X-ray diffraction (XRD) measurements were carried out with a Phillips X'pert MPD diffractometer using $\mathrm{Cu} \mathrm{K} \alpha$ radiation.

The transmittance spectra of the nanocomposite films were collected with a UV-vis Spectrophotometer (PerkinElmer UV 850) equipped with a $15 \mathrm{~cm}$ diameter integrating sphere bearing the holder in the horizontal position. Spectra were recorded at room temperature in steps of $1 \mathrm{~nm}$, in the range $400-700 \mathrm{~nm}$.

TGA essays were carried out using a Shimadzu TGA 50 analyser equipped with a platinum cell. Samples were heated at a constant rate of $10^{\circ} \mathrm{C} / \mathrm{min}$ from room temperature to $800^{\circ} \mathrm{C}$ under a nitrogen flow of $20 \mathrm{~mL} / \mathrm{min}$. The thermal decomposition temperature was taken as the onset of significant $(\sim 0.5 \%)$ weight loss, after the initial moisture loss.

Dynamic mechanical analyses (DMA) were performed on a Tritec 2000 DMA (Triton Technologies) using tension as deformation mode (single strain). For the temperature sweeps, a ramp rate of $2^{\circ} \mathrm{C} / \mathrm{min}$ was used, and samples were heated from -100 to $200^{\circ} \mathrm{C}$, at a frequency of 1 and $10 \mathrm{~Hz}$, with a displacement of $0.005 \mathrm{~mm}$. Samples' average dimensions of the films were approximately $5 \times 5 \times 0.2 \mathrm{~mm}$. Tg values were determined using the maximum of the $\tan \delta$ curve. Films used for DMA tests were kept in a conditioning cabinet at $50 \%$ relative humidity $(\mathrm{RH})$ and $30^{\circ} \mathrm{C}$ to ensure the stabilization of their water content. PHEMA polymers (also previously conditioned) were analysed using the material pocket accessory in deformation mode.

The swelling ratio (SR) of the nanocomposite films was measured using the weighing method [5]. Specimens (dimensions $1 \times 1 \mathrm{~cm}$ ) were immersed in distilled water at room temperature to study their swelling in a minimum of three samples (tested for each material). The weight increase was periodically assessed for 2 days. Samples were taken out of the water; their wet surfaces were immediately wiped dry in filter paper and then reimmersed. Then the SR was calculated using equation (1)

$$
\operatorname{SR}(\%)=\frac{\left(W_{s}-W_{d}\right)}{W_{d}} \times 100 \% \text {, }
$$

where $W_{d}$ is the initial weight of dry film and $W_{s}$ is the weight of the film swollen in water. 


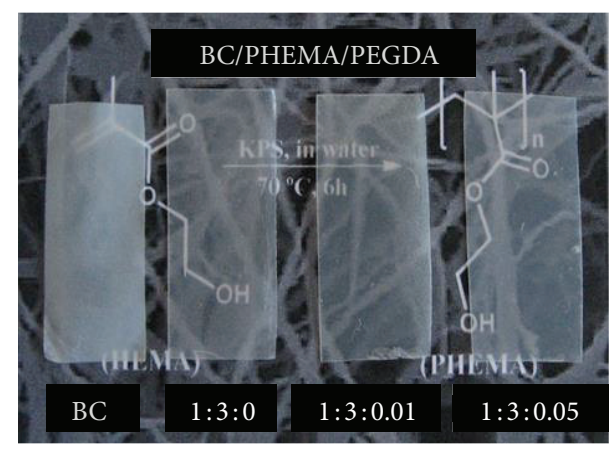

(a)

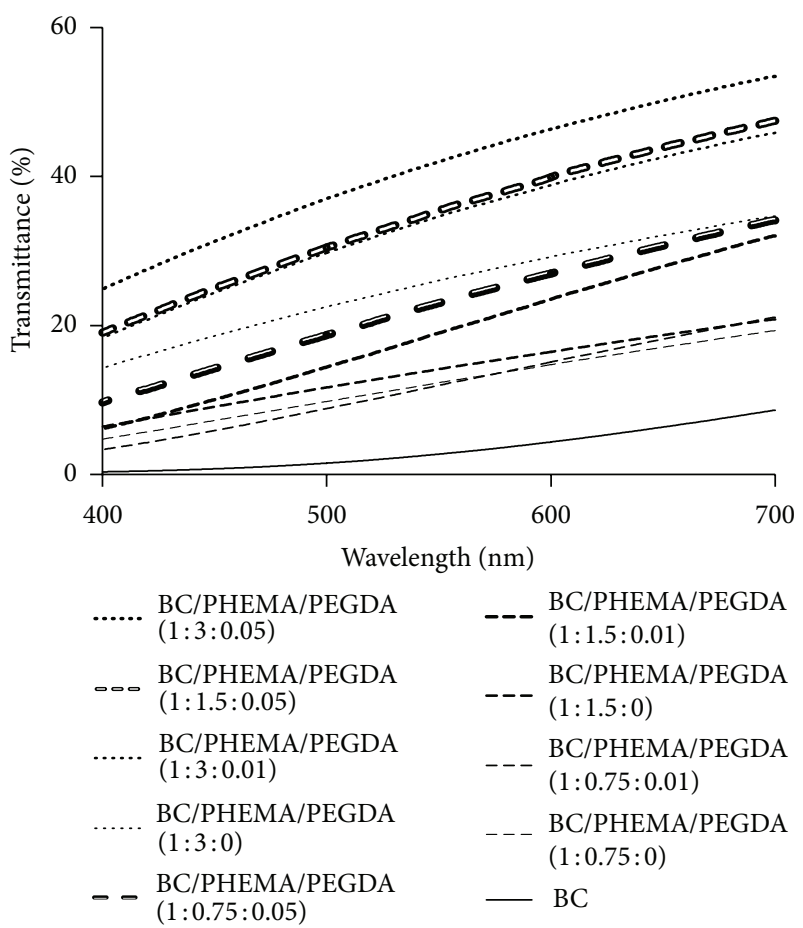

(b)

FIGURE 2: (a) Visual aspect and (b) transmittance of the different nanocomposite films.

2.4. In Vitro Cell Response. Adipose-derived stem cells (ADSCs) were used in a short-term standard cytotoxicity assay of BC and BC/PHEMA/PEGDA (1:3:0.05) membranes. The procedure and methods are described elsewhere [38]. Briefly, membranes $\left(6 \mathrm{~cm}^{2}\right.$ of area, $\leq 0.5 \mathrm{~mm}$ thick) were sterilized with $70 \%$ ethanol for $2 \mathrm{~h}$ at room temperature and rinsed with phosphate buffered saline (PBS) aqueous solutions for $1 \mathrm{~h}$. To prepare extracts of test materials according to the international standard ISO 1099312, sterilized samples were incubated in ADSCs growth medium, consisting in Dulbecco's modified Eagle's medium ((DMEM) Sigma Chemicals Co., USA), supplemented with Glutamax (Sigma) and 10\% fetal bovine serum ((FBS) Gibco), at $37^{\circ} \mathrm{C}$ for $24 \mathrm{~h}$. The ratio of material surface/extract fluid was constant and equal to $6 \mathrm{~cm}^{2} / \mathrm{mL}$.

For in vitro cytotoxicity assays, ADSCs were seeded and allowed to grow for $24 \mathrm{~h}$ in 96 -well microplates at a density of $4 \times 10^{3}$ cells/well in the presence of standard culture medium. Then, cultures were treated for 24,48 , and $72 \mathrm{~h}$ with the previously prepared extracted media. In addition, high-density polyethylene (negative control, USP Rockville, USA) and poly(vinyl chloride) (positive control, Portex, UK) were used. The metabolic activity of viable cells was determined by a colorimetric assay (Cell Proliferation Kit I MTT, Roche). Briefly, only viable cells could reduce MTT to formazan pigment, which is then dissolved in dimethylsulfoxide (DMSO). The cell number per well is proportional to the recorded absorbance of formazan at $550 \mathrm{~nm}$, using an ELISA microplate reader. All assays were conducted in triplicate, and each experiment was repeated three times. Mean values and their standard deviations were calculated.

To analyze ADSCs seeding and proliferation onto the films, scanning electron microscopy (SEM) studies were carried out on cultured human ADSCs on BC and BC/PHEMA/PEGDA $(1: 3: 0.05)$ membranes. Aliquots containing $5 \times 10^{4}$ cells were seeded, under static conditions, onto BC and BC/PHEMA/PEGDA (1:3:0.05) membranes in ultralow attachment 24-well culture plates (Costar) prewetted with standard culture medium. The cultures were incubated for $72 \mathrm{~h}$ to allow attachment and proliferation $\left(37^{\circ} \mathrm{C}, 5 \% \mathrm{CO}_{2}\right.$, and $\left.95 \% \mathrm{RH}\right)$. Subsequently, samples were rinsed with $\mathrm{PBS}$ to remove nonattached cells, fixed with $2 \%$ glutaraldehyde in a cacodylate buffer $(0.1 \mathrm{M}, \mathrm{pH}=7.4)$ and postfixed using $\mathrm{OsO}_{4}$ for $1 \mathrm{~h}$, washed in phosphate buffer solution, and dehydrated using series of graded ethanol solutions. Samples were dried through $\mathrm{CO}_{2}$ critical point, gold sputtered, and analyzed in a SA-3400N Hitachi microscope. The voltage used was $15.0 \mathrm{kV}$, and magnifications selected for SEM images range from 1500 to $10000 x$.

\section{Results and Discussion}

A series of BC/PHEMA nanocomposite films was prepared by varying the amounts of monomer (HEMA) and crosslinker (PEGDA) impregnated into the $\mathrm{BC}$ membranes prior to the polymerization step (Table 1). All obtained nanocomposite films were very homogeneous (Figure 2(a)) and considerably more translucent than the pristine $\mathrm{BC}$ membrane. 


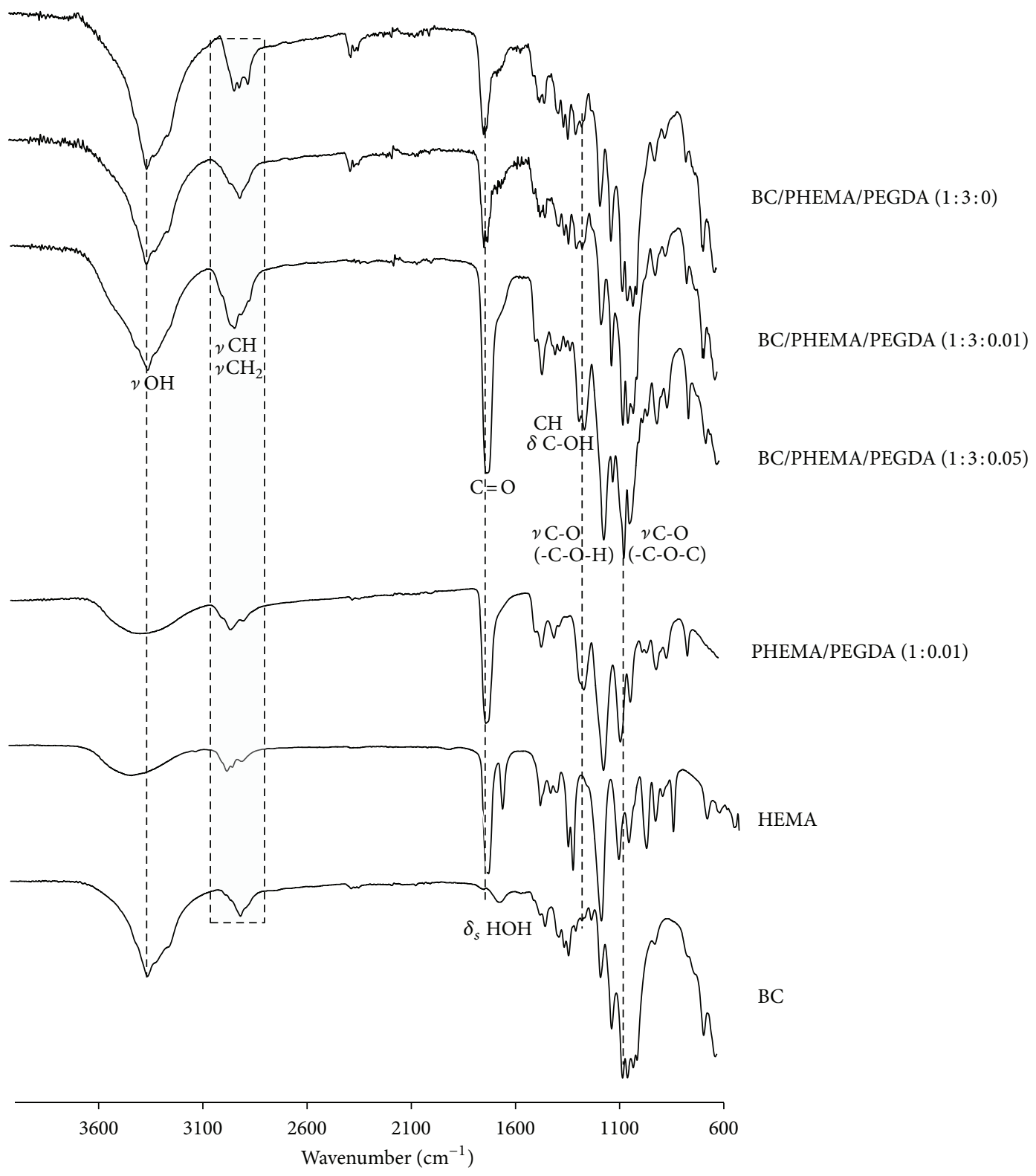

FIGURE 3: FTIR spectra of BC, HEMA, PHEMA/PEGDA (1:0.01), and BC/PHEMA nanocomposite films $(1: 3)$.

The amount of polymer imbibed in BC was shown to systematically grow with the amount of HEMA added as well as with the amount of cross-linker (PEGDA). In this last case, cross-linking will prevent PHEMA to be drained from BC network during washing or afterwards during any application of the material.

Figure 2(b) shows the light transmittance of all $\mathrm{BC} /$ PHEMA nanocomposite films, in the range of 400-700 nm. The incorporation of PHEMA polymeric chains into the $\mathrm{BC}$ nanofibrils network increases considerably the transmittance of the films, because of the inherent high transparency of this polymer [39] and of its excellent compatibility with the BC nanofibrils. The translucency increases with the amount of monomer and for the same monomer content increases also with the cross-linker content, confirming the expected higher retention of PHEMA inside the BC network promoted by the cross-linking of the polymeric chains.

3.1. Structural Characterization. The success of the polymerization reaction inside $\mathrm{BC}$ membranes was confirmed by FTIR and NMR analyses.

Figure 3 shows the FTIR spectra of BC, HEMA, and PHEMA (prepared in the same conditions but without cellulose and cross-linker) and of BC/PHEMA nanocomposites with higher content of PHEMA as an example (series BC/PHEMA/PEGDA ( $1: 3)$ ). All BC/PHEMA films produced by this methodology present, as expected, an FTIR spectral trace correspondent to the sum of both components (BC and PHEMA). The success of the polymerization of HEMA inside the $\mathrm{BC}$ membranes was confirmed by the appearance in the 


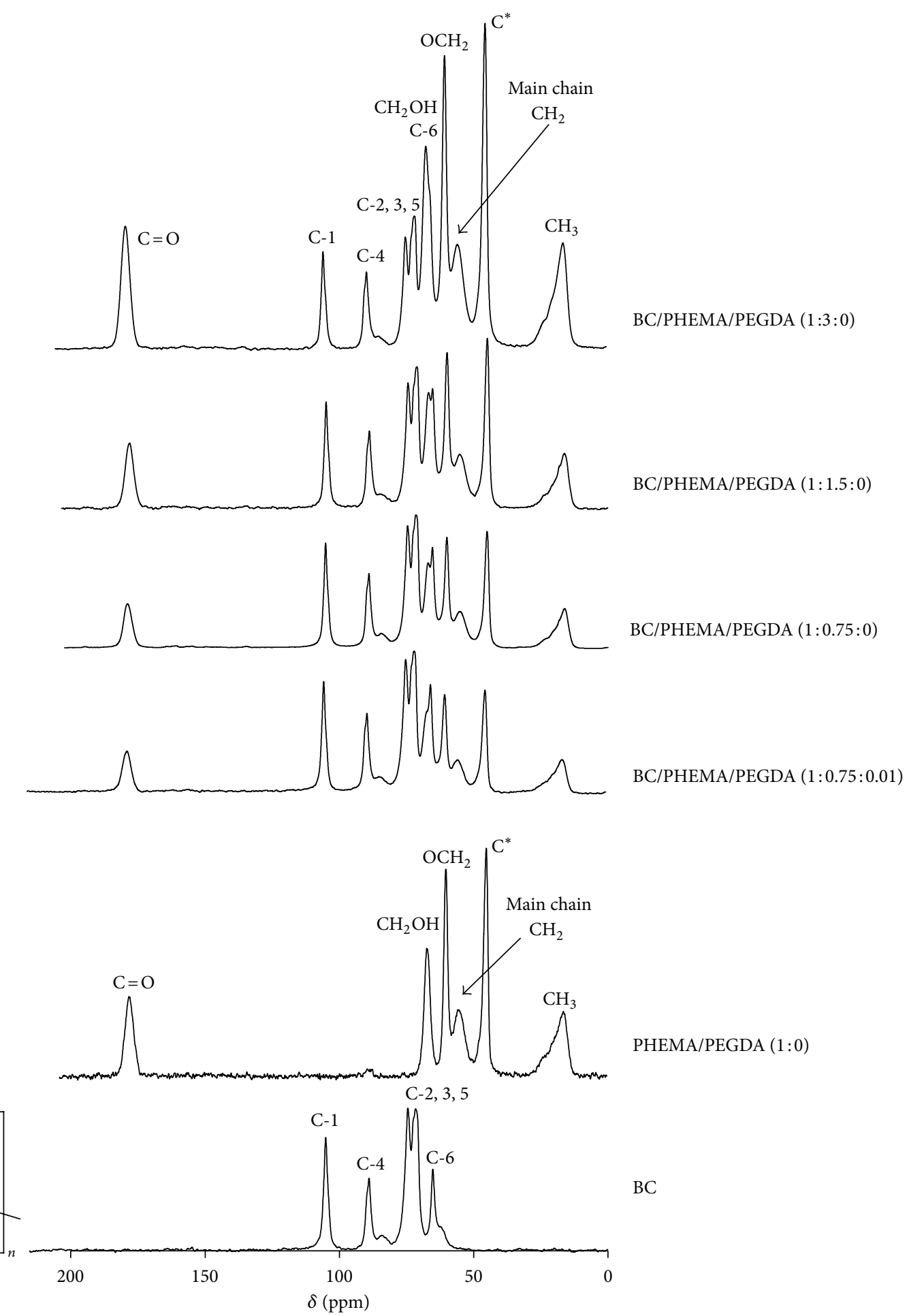

FIGURE 4: CPMAS ${ }^{13}$ C NMR spectra of nanocomposite films, BC/PHEMA/PEGDA (1:3:0), $(1: 1.5: 0)$, and (1:0.75:0), BC/PHEMA/PEGDA $(1: 0.75: 0.01)$ and of PHEMA/PEGDA $(1: 0)$ and BC.

films of an intense band at around $1716 \mathrm{~cm}^{-1}$, attributed to the carbonyl ester group stretching vibrations in the polymer and to the concomitant disappearance of the band at $1634 \mathrm{~cm}^{-1}$ and of the sharp peak at $814 \mathrm{~cm}^{-1}$, assigned, respectively, to the $\mathrm{C}=\mathrm{C}$ stretching vibration and to $\mathrm{C}-\mathrm{H}$ out-of-the-plane bending vibration, from the vinyl group of the monomer. The bands at 1447 and $747 \mathrm{~cm}^{-1}$, associated with the bending vibration mode of $\mathrm{CH}_{2}$ and $\mathrm{CH}_{2}$ rocking, characteristic of methacrylic polymers are also a confirmation of the successful formation of PHEMA inside the BC network. Finally, 

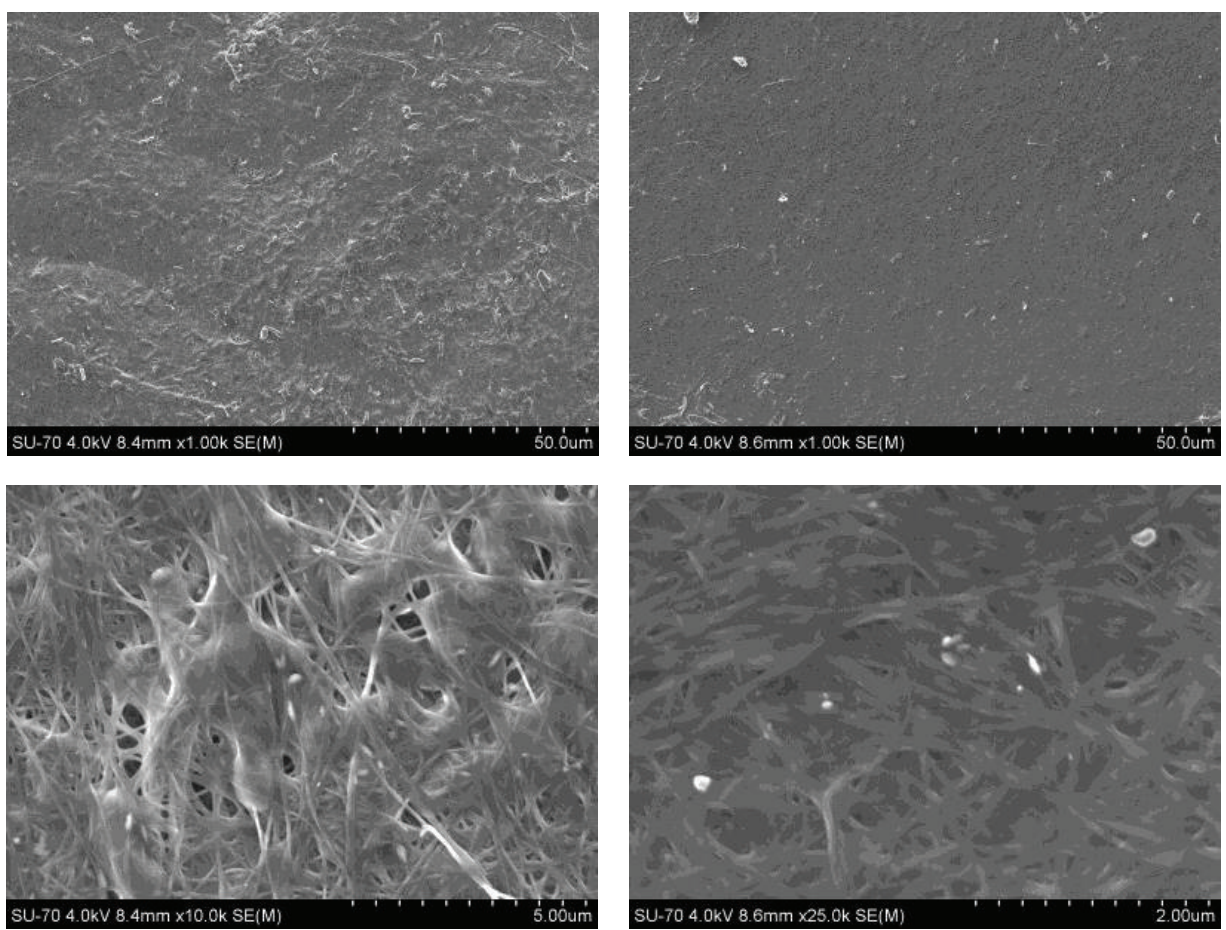

(a)
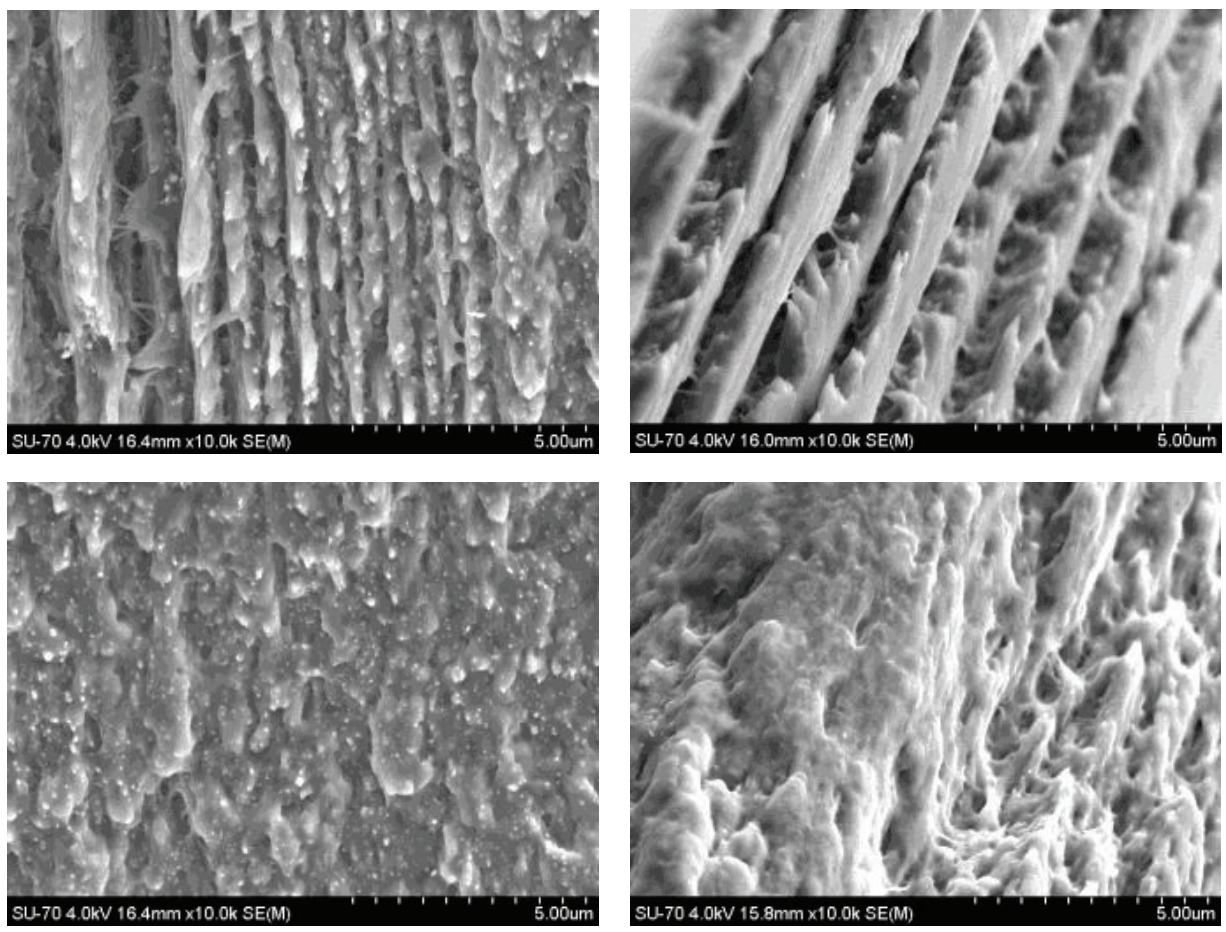

(b)

Figure 5: SEM micrographs of BC/PHEMA/PEGDA (1:3:0) (left) and BC/PHEMA/PEGDA (1:3:0.05) (right) nanocomposite films, recorded from surfaces (a) and cross-sections (b).

the vibrations at $3350 \mathrm{~cm}^{-1}$ (O-H stretching), $2930 \mathrm{~cm}^{-1}$ (C$\mathrm{H}$ stretching), and $1245 \mathrm{~cm}^{-1}$ (stretching of C-O) are typical of both $\mathrm{BC}$ and PHEMA. Moreover, the comparison of the normalized FTIR spectra of the BC/PHEMA/PEGDA $(1: 3)$ nanocomposite series clearly confirmed that the amount of PHEMA retained inside the $\mathrm{BC}$ network increased with the cross-linker content based on the increment of the intensity of the characteristic bands of PHEMA, namely, the carbonyl 


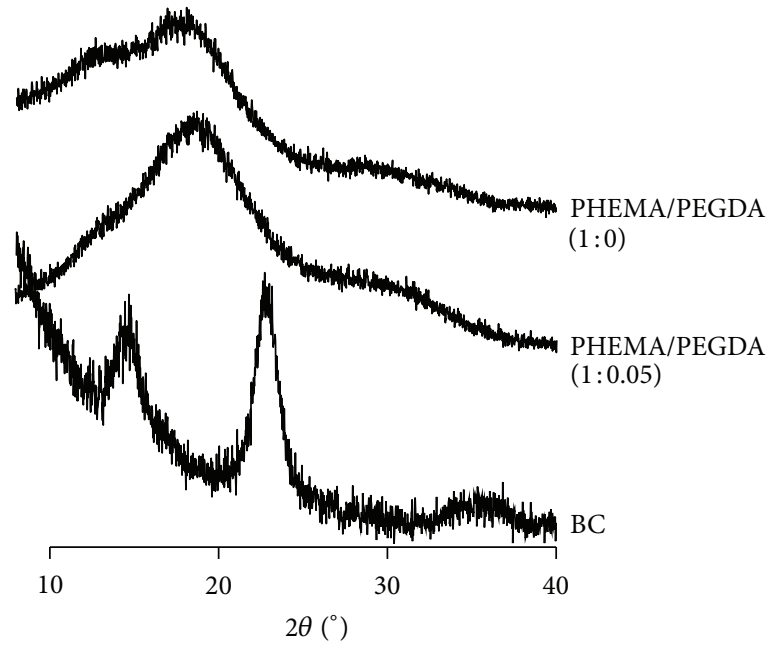

(a)

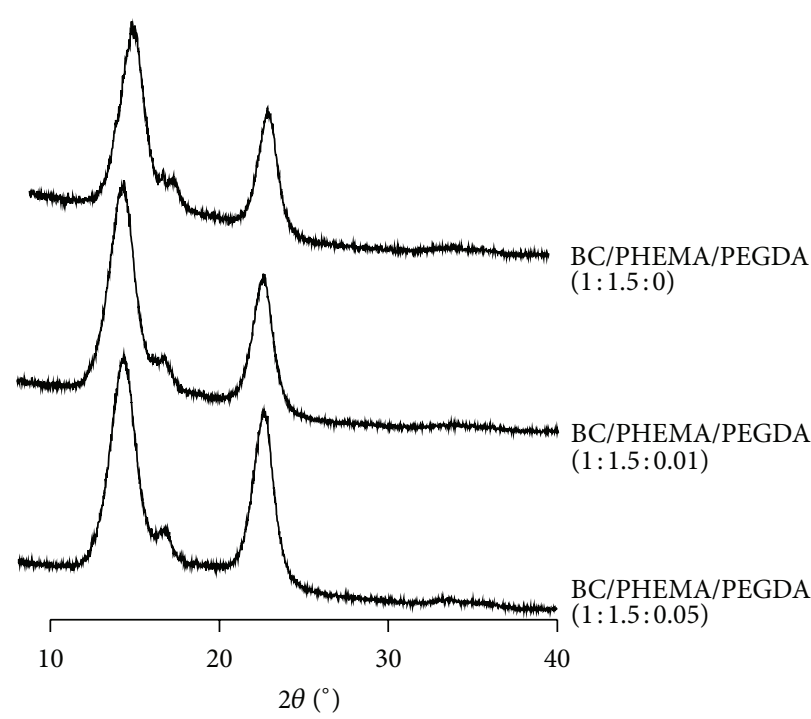

(c)

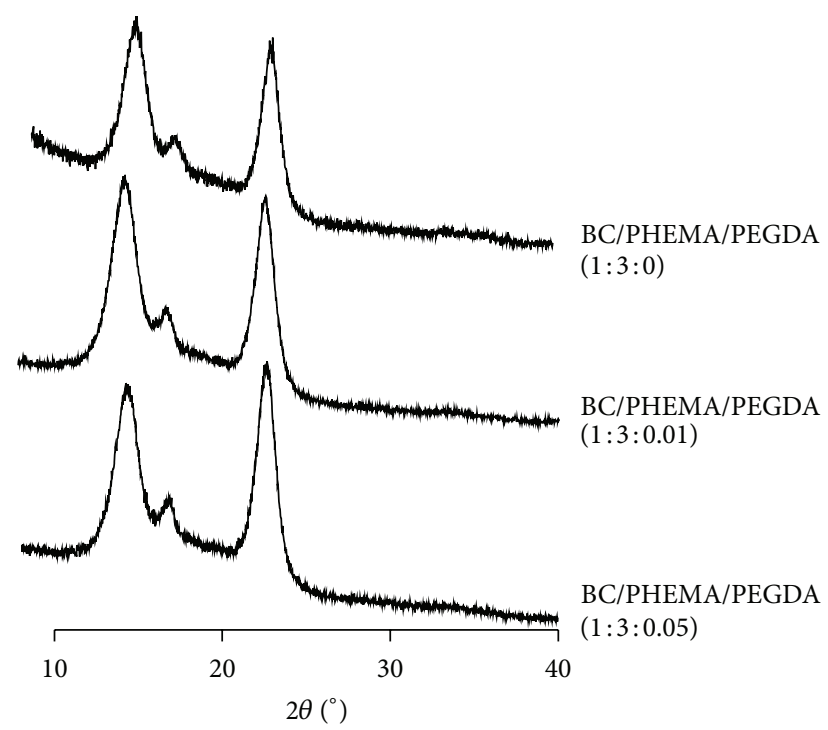

(b)

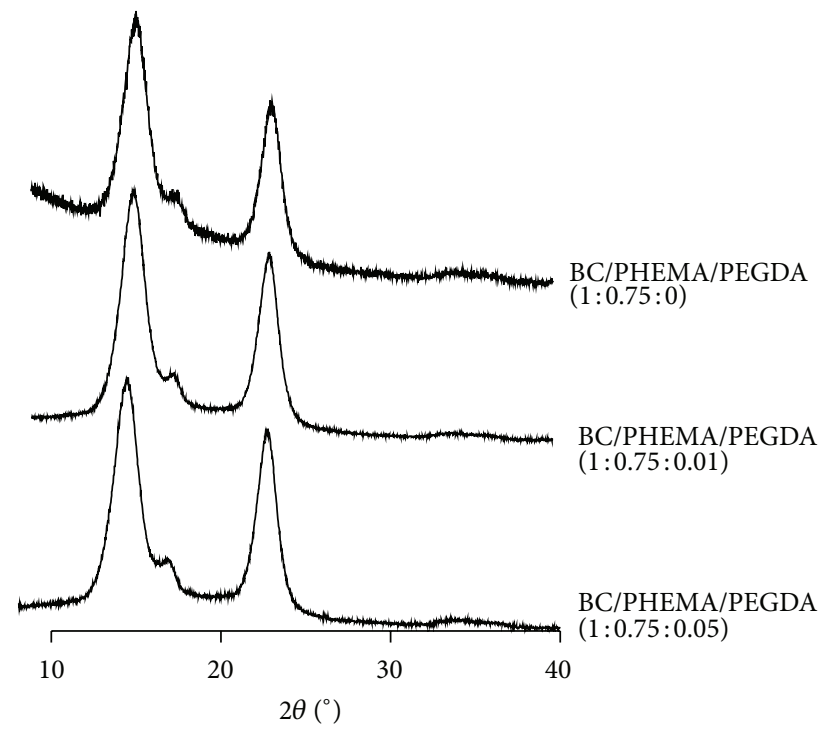

(d)

FIGURE 6: X-ray diffractograms of the nanocomposite films, polymers (with and without cross-linker), and BC.

ester stretching vibrations at around $1715 \mathrm{~cm}^{-1}$. This tendency was also observed for the other series (BC/PHEMA/PEGDA $(1: 1.5)$ and BC/PHEMA/PEGDA $(1: 0.75))$ and is in close agreement with the transmittance results described above.

Figure 4 displays the solid state CPMAS ${ }^{13} \mathrm{C}$ NMR spectra of selected BC/PHEMA nanocomposite films, namely, BC/PHEMA/PEGDA $(1: 3: 0)$, BC/PHEMA/PEGDA $(1: 1.5: 0), \quad$ BC/PHEMA/PEGDA $(1: 0.75: 0)$, and $\mathrm{BC} /$ PHEMA/PEGDA $(1: 0.75: 0.01)$ as well as of starting components, $\mathrm{BC}$, and PHEMA. It is evident that, the ${ }^{13} \mathrm{C}$ NMR spectra of the BC/PHEMA nanocomposites are also a sum of the resonances typical of BC carbons at $\delta 65.2$ (C-6), 71.4-74.3 (C-2,3,5), 90.0 (C-4), and 104.8 ppm (C-1) and of PHEMA at 16.2-23.2 $\left(\alpha-\mathrm{CH}_{3}\right), 45.0$ (quaternary $\mathrm{C}$ ), $55.4\left(\mathrm{CH}_{2}\right.$ main chain), $60.1\left(-\mathrm{O}-\underline{\mathrm{CH}}_{2}\right), 67.2\left(\mathrm{HO}-\mathrm{CH}_{2}-\right)$, and finally $178.2 \mathrm{ppm}$ assigned to $\mathrm{C}=\mathrm{O}$. Carbon resonances specific of PEGDA are not visible due to the low content of this last component. The intensity of the PHEMA carbon resonances compared to those of $\mathrm{BC}$ increases with the proportion of monomer and cross-linker (data not shown) used in each experiment, reflecting different polymer contents, which is in good agreement with the FTIR analysis and the weight gains reported above (Table 1).

The absence of FTIR vibrations or ${ }^{13} \mathrm{C}$ resonances typical of the monomer (or of other contaminants) in the FTIR and NMR spectra of the nanocomposites demonstrates the complete consumption/removal of all reactants/byproducts during the polymerization and washing steps which is a crucial aspect when considering biomedical applications. 


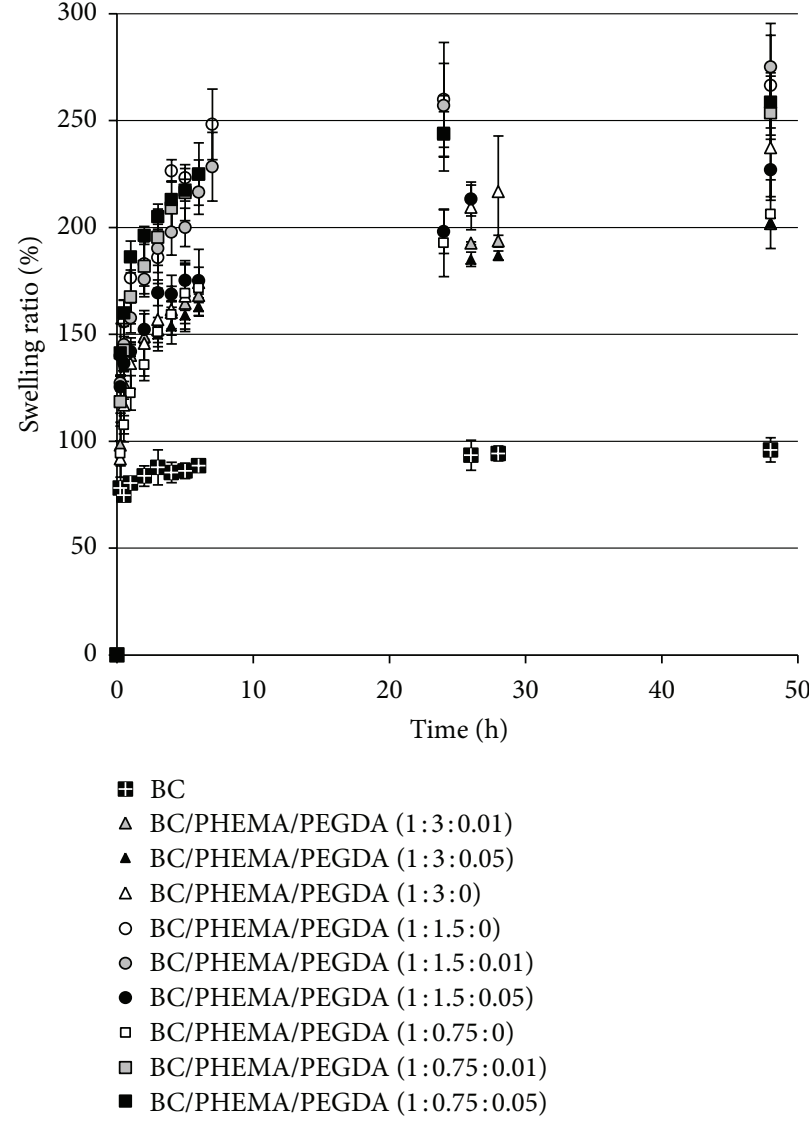

(a)

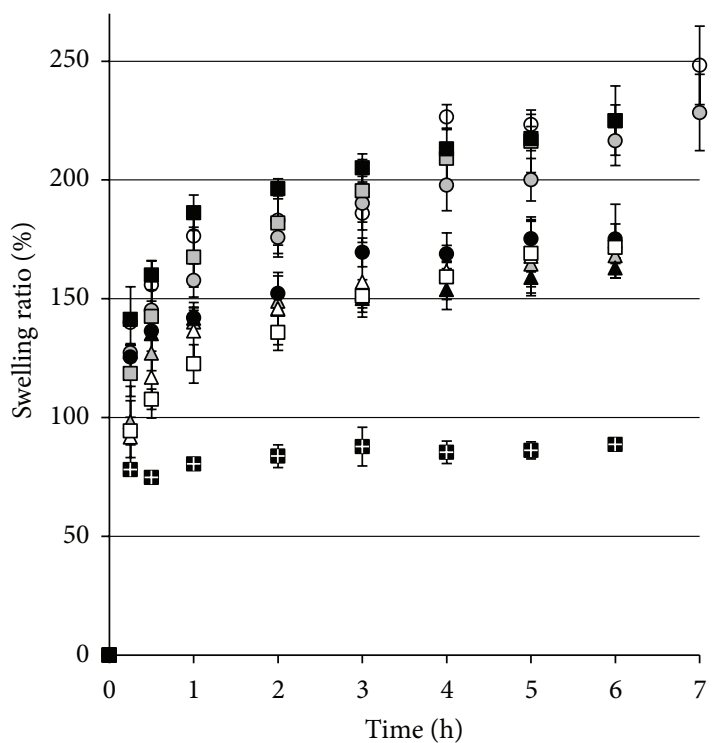

\# $\mathrm{BC}$

$\triangle$ BC/PHEMA/PEGDA $(1: 3: 0.01)$

\ BC/PHEMA/PEGDA $(1: 3: 0.05)$

$\triangle$ BC/PHEMA/PEGDA $(1: 3: 0)$

○ BC/PHEMA/PEGDA $(1: 1.5: 0)$

- BC/PHEMA/PEGDA $(1: 1.5: 0.01)$

- BC/PHEMA/PEGDA $(1: 1.5: 0.05)$

- BC/PHEMA/PEGDA $(1: 0.75: 0)$

口 BC/PHEMA/PEGDA $(1: 0.75: 0.01)$

- BC/PHEMA/PEGDA $(1: 0.75: 0.05)$

(b)

Figure 7: (a) Plot of the swelling ratio as a function of time of all BC/PHEMA nanocomposite films and BC membrane (0-48 h). (b) Expansion $0-7 \mathrm{~h}$.

3.2. Morphology Characterization. A selection of SEM micrographs of the surface of BC/PHEMA (1:3) nanocomposites with $0 \%$ and $5 \%$ of cross-linker is shown in Figure 5(a).

The characteristic tridimensional nanofibrillar network of BC [24, 38] was clearly observed in the surface of all nanocomposite films indicating that this was not affected by the polymerization reaction. In addition, the cellulose nanofibrils are perfectly embedded within the PHEMA matrix. The nanocomposites without cross-linker displayed a less homogenous morphology, with several unfilled parts, suggesting a considerable superficial lixiviation of PHEMA during the washing step.

For the same nanocomposite films a selection of SEM micrographs of the fractured zones (cross-section) is shown in Figure 5(b). For each sample, two different magnifications were used in order to display the distribution of PHEMA in the $\mathrm{BC}$ network and the interfacial adhesion between the two composite components. The cross-section micrographs of both nanocomposite films displayed the typical lamellar morphology of BC completely impregnated with PHEMA. These images also provided evidence of the strong interfacial adhesion between BC nanofibrils and PHEMA, as shown by the nanofibers breakage during fracturing and the homogeneous dispersion of the matrix within the $\mathrm{BC}$ network. This behaviour is obviously due to the excellent compatibility between BC and PHEMA that arises from the potential establishment of hydrogen bonds between them. These results clearly support the superior mechanical properties of the BC/PHEMA nanocomposites, as suggested by the mechanical tests discussed below.

3.3. X-Ray Diffraction Characterization. X-ray diffraction analyses have been performed on neat BC membranes, PHEMA matrices (with different amounts of cross-linker), and all BC/PHEMA nanocomposite films (Figure 6).

As it is well known, BC exhibits a diffractogram typical of Cellulose I (native cellulose), with the main diffraction peaks at $2 \theta 14.3,15.9,22.6$, and $33.7^{\circ}$ [40], while all PHEMA matrices are characterized by a broad peak centred at around $2 \theta 18^{\circ}$, typical of fully amorphous materials. The X-ray diffraction profiles of the BC/PHEMA nanocomposite films only showed that the typical diffraction peaks of $\mathrm{BC}$ and their magnitude increases, as expected, with the BC content. For the nanocomposite films with lower cross-linker content these peaks are quite evident. In fact, the diffractograms of these materials look very closely to that of BC. The increase on crystallinity observed for the nanocomposite films, together with the unique BC morphology, is closely 


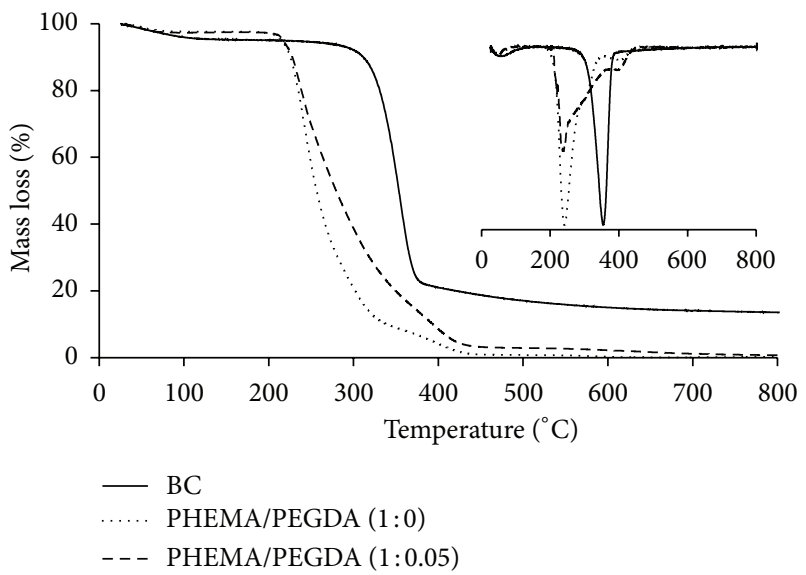

(a)

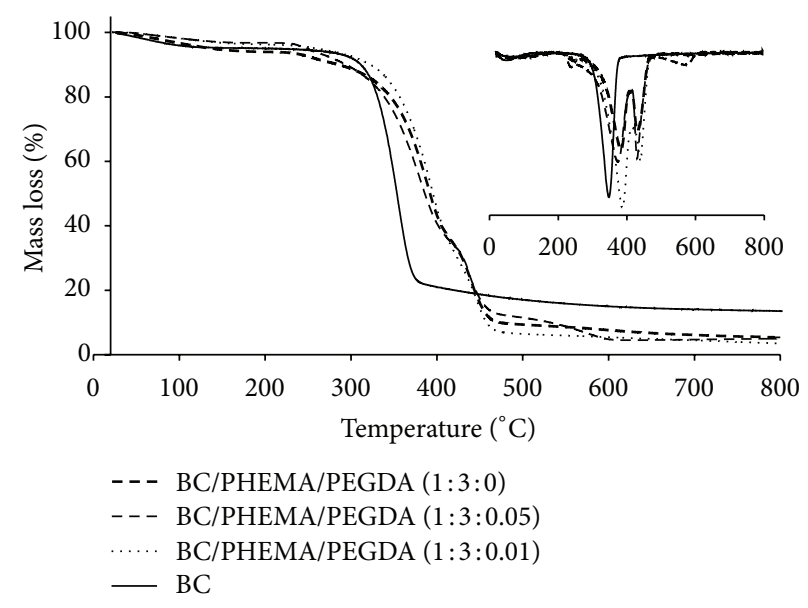

(b)

Figure 8: (a) TGA thermograms of BC and PHEMA/PEGDA (1:0) and PHEMA/PEGDA (1:0.05). (b) TGA thermograms of BC/PHEMA/ PEGDA $(1: 3: 0)$, BC/PHEMA/PEGDA $(1: 3: 0.01)$, and BC/PHEMA/PEGDA $(1: 3: 0.05)$.

related to the improvement of the mechanical performance of the PHEMA/BC based films discussed later.

3.4. Swelling Behaviour. Swelling studies were performed in order to evaluate the rehydration ability of the nanocomposite films by their immersion in water during at least $48 \mathrm{~h}$ (reverse swelling after drying). Swelling ratios of the native $\mathrm{BC}$ membrane (for comparison) and BC/PHEMA nanocomposite films are presented in Figure 7 (a) $(0-48 \mathrm{~h})$ and Figure 7(b) (expansion, 0-7 h). All samples absorbed water during the experiment, following similar patterns. After a relatively fast water uptake during the first hour, the water absorption slowed down, leading gradually to a plateau after 24 hours. However, the BC/PHEMA nanocomposite films showed a considerably higher swelling ratio than $\mathrm{BC}$ membranes, specifically $200-270 \%$ and $100 \%$, respectively. This behaviour is attributed to the presence of the hydrophilic PHEMA polymeric chains within the nanostructured BC network which additionally prevents the collapse of $\mathrm{BC}$ nanostructure during drying.

The PHEMA content in the nanocomposites, that is, the amount of PHEMA retained in the BC network, is strictly related to the improvement on their swelling ratio being in general higher for those with cross-linker, which is in close agreement with the NMR and FTIR analyses. These nanocomposites increase the water retention capacity of $\mathrm{BC}$, in its film form, originating improved $\mathrm{BC}$ nanocomposite films suitable for several biomedical applications, such as, wound healing and topical drug delivery.

3.5. Thermal Properties. Thermogravimetric analysis of BC/PHEMA nanocomposite films was carried out to evaluate their thermal stability and degradation profile (Table 2, Figure 8). The thermal stability is a quite important aspect in several applications where materials might be submitted to high temperatures, such as sterilization in the case of biomedical materials. Reference BC membrane and
TABLE 2: Thermal degradation profiles of the studied nanocomposite films.

\begin{tabular}{lcccc}
\hline $\begin{array}{l}\text { BC/PHEMA } \\
\text { nanocomposites }\end{array}$ & $\begin{array}{c}\% \text { mass } \\
\text { loss at } \\
100^{\circ} \mathrm{C}\end{array}$ & $\begin{array}{c}\text { Tdi } \\
\left({ }^{\circ} \mathrm{C}\right)\end{array}$ & $\begin{array}{c}\text { Tdmaxl } \\
\left({ }^{\circ} \mathrm{C}\right)\end{array}$ & $\begin{array}{c}\text { Tdmax2 } \\
\left({ }^{\circ} \mathrm{C}\right)\end{array}$ \\
\hline $\begin{array}{l}\text { BC/PHEMA/PEGDA } \\
(1: 3: 0)\end{array}$ & 3.36 & 272 & 384 & 434 \\
$\begin{array}{l}\text { BC/PHEMA/PEGDA } \\
(1: 3: 0.01)\end{array}$ & 1.79 & 274 & 388 & 442 \\
$\begin{array}{l}\text { BC/PHEMA/PEGDA } \\
(1: 3: 0.05)\end{array}$ & 1.79 & 250 & 373 & 434 \\
$\begin{array}{l}\text { BC/PHEMA/PEGDA } \\
(1: 1.5: 0)\end{array}$ & 2.95 & 276 & 395 & 443 \\
$\begin{array}{l}\text { BC/PHEMA/PEGDA } \\
(1: 1.5: 0.01)\end{array}$ & 2.25 & 266 & 387 & 440 \\
$\begin{array}{l}\text { BC/PHEMA/PEGDA } \\
(1: 1.5: 0.05)\end{array}$ & 2.81 & 257 & 373 & 430 \\
$\begin{array}{l}\text { BC/PHEMA/PEGDA } \\
(1: 0.75: 0)\end{array}$ & 3.03 & 276 & 389 & 442 \\
$\begin{array}{l}\text { BC/PHEMA/PEGDA } \\
(1: 0.75: 0.01)\end{array}$ & 2.06 & 272 & 390 & 441 \\
$\begin{array}{l}\text { BC/PHEMA/PEGDA } \\
(1: 0.75: 0.05)\end{array}$ & 2.44 & 235 & 386 & 433 \\
\hline
\end{tabular}

PHEMA matrices (with and without cross-linker) were also analysed for comparison purposes (Figure 8).

BC showed a single weight-loss feature, typical of cellulosic substrates, with initial and maximum decomposition temperatures at around 260 and $350^{\circ} \mathrm{C}$, respectively [41]. The mass loss at around $100^{\circ} \mathrm{C}$ is associated with the volatilization of residual water. PHEMA matrices are considerably less stable than BC since they start to decompose at around $200^{\circ} \mathrm{C}$ and presented a degradation profile with three main degradation steps at about 230,290 , and $400^{\circ} \mathrm{C}$ (Figure 8) [42]. The cross-linking of PHEMA with small amounts of 


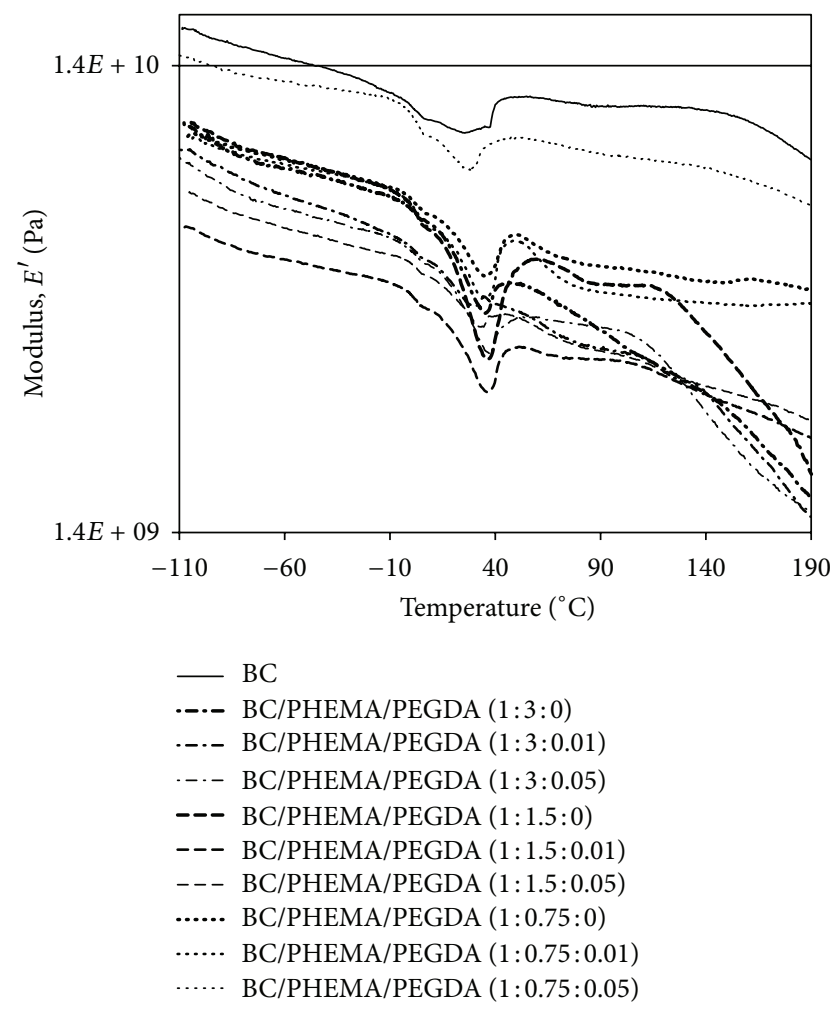

Figure 9: Storage moduli versus temperature of BC and all nanocomposite films. DMA analyses were carried out in tension mode $(1 \mathrm{~Hz})$. All the samples were conditioned at $50 \% \mathrm{RH}$.

PEGDA (up to 5\%) had no measurable effect on the thermal stability of the polymer.

The TGA tracing of BC/PHEMA nanocomposite films is not a sum of those of the individual components since they showed in general a two-step weight-loss degradation profile with maximum degradation temperatures at 370-390 and $430-440^{\circ} \mathrm{C}$ (Table 2, Figure 8). The distinct degradation profiles and the considerable increments on the $\mathrm{Ti}$ and Tdmax of the nanocomposites when compared with $\mathrm{BC}$ and PHEMA clearly suggest a strong interaction between them and thus excellent compatibility, as previously observed by SEM. This is probably associated with the establishment of strong interactions (hydrogen bonds) between $\mathrm{BC}$ nanofibrils and PHEMA chains. The range of PHEMA percentage in the nanocomposites studied here hardly had any effect on the thermal stability and degradation profile of the films.

3.6. Dynamic Mechanical Properties. Figure 9 shows the variation of the storage tensile modulus of BC and BC/PHEMA nanocomposite films as a function of temperature. Specifically, the effect of the amount of PHEMA (and BC) and crosslinker on the viscoelastic properties of the nanocomposites was assessed.

For neat $\mathrm{BC}$ membranes the variation of $E^{\prime}$ as a function of temperature only showed a minor transition at around $40^{\circ} \mathrm{C}$ attributed to the release of residual water molecules which are known to act as plasticizers. This transition was also

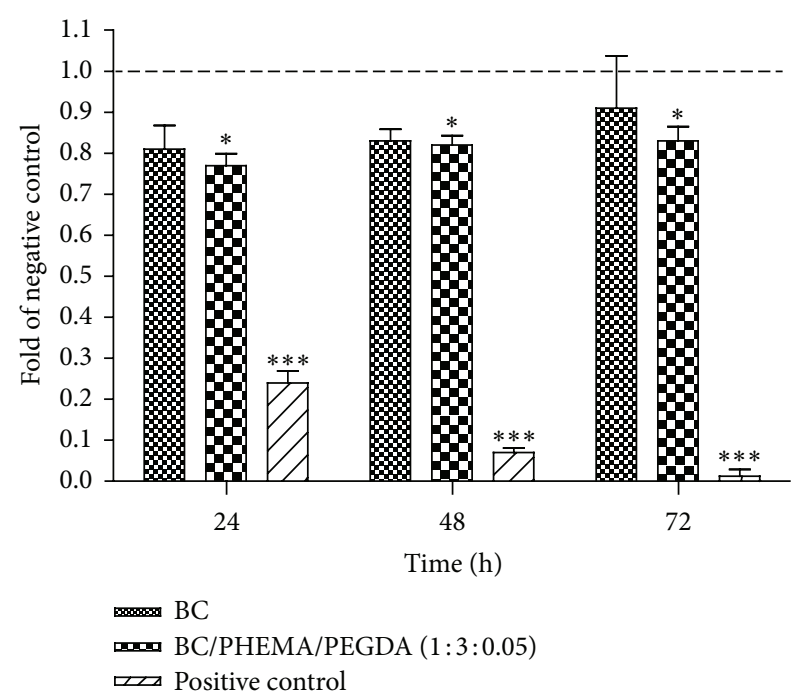

FIGURE 10: ADSCs proliferation in contact with BC, BC/PHEMA/ PEGDA $(1: 3: 0.05)$ membranes, and positive and negative control during 24, 48, and $72 \mathrm{~h}$. Data are presented as mean \pm standard deviation of three independent experiments $\left({ }^{*} P<0.05\right)$.

observed in all BC/PHEMA nanocomposites since PHEMA is also considerably hydrophilic. For the nanocomposite films with higher PHEMA contents (Table 1), an additional transition was registered in the range $100-160^{\circ} \mathrm{C}$, with a maximum decrease at around $125^{\circ} \mathrm{C}$. This drastic drop of the tensile storage modulus $E^{\prime}$ is typical of a relaxation phenomenon associated with the glass-rubber transition of the PHEMA matrix [43], as further confirmed by the analysis of neat PHEMA.

As expected all nanocomposites showed lower storage moduli than that of neat BC because PHEMA matrices are amorphous and thus less rigid than the $\mathrm{BC}$ membrane which is a highly crystalline material. These results clearly indicate that a set of BC/PHEMA nanocomposite films with distinct mechanical performances (but similar thermal stabilities) can be easily designed by simply varying the BC/PHEMA percentage contents as well as the percentage of crosslinker. Thus this strategy consists in a simple approach to obtain PHEMA based nanocomposite films for applications requiring diverse mechanical performances.

3.7. Biocompatibility. The effect of the introduction of PHEMA polymeric chains into the BC membrane network on the viability, proliferation, and cell adhesion of human ADSCs was studied. A wide variety of cell lines have been recently used to determine cytotoxicity and biocompatibility of novel materials based on BC, including ADSCs [44]. This type of cells has emerged as an important tool for tissue engineering because they exhibit capacity to differentiate into mesodermal cell lineages, largely to bone, cartilage, and adipocytes $[45,46]$.

Figure 10 shows the cell viability based on the cell growth ratio between extracted fluid from samples and negative control. As expected, standard growth values were obtained with 

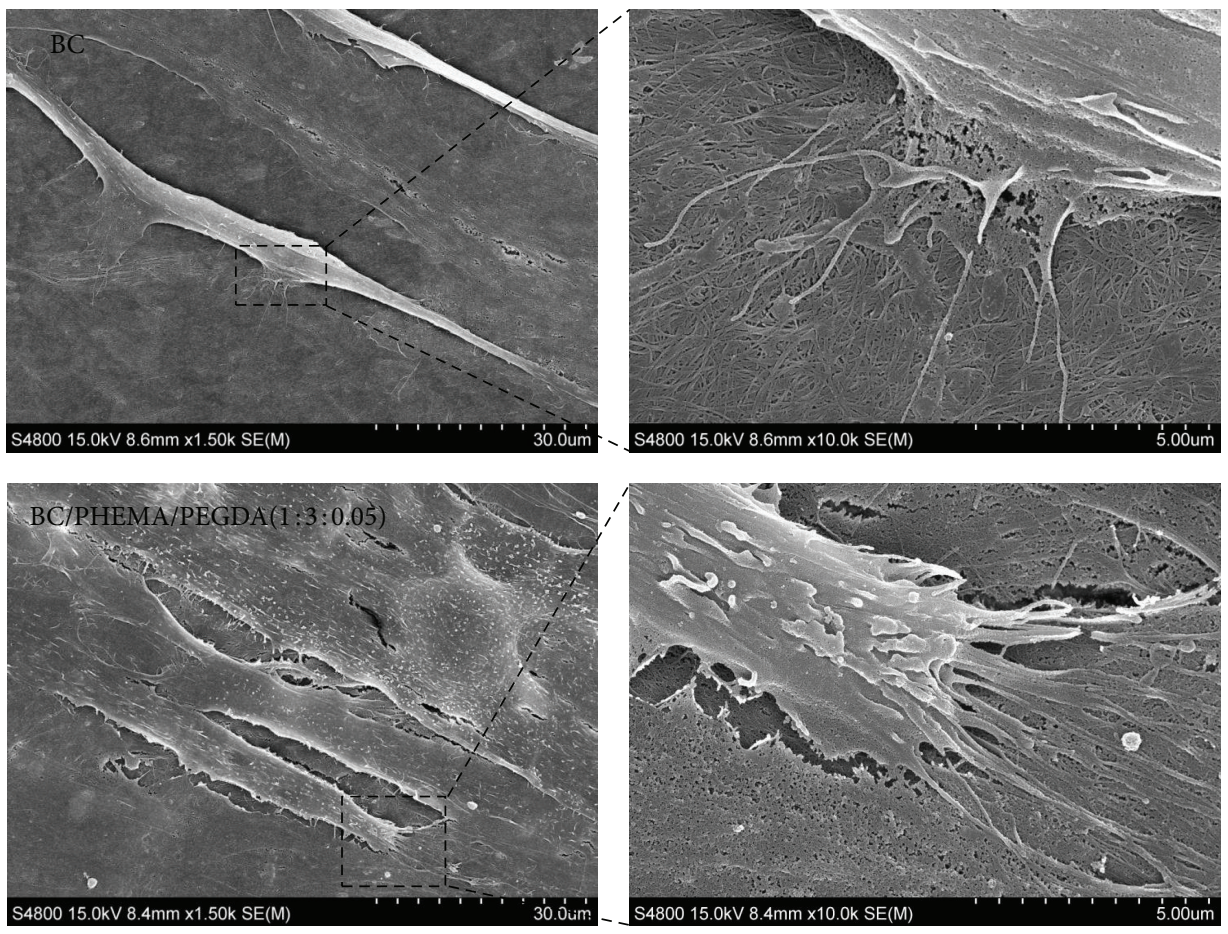

FIGURE 11: SEM images showing morphology of ADSCs at $72 \mathrm{~h}$ after seeding on the surface of BC and BC/PHEMA/PEGDA (1:3:0.05) membranes.

the negative control (high-density polyethylene (HDPE)) and a dramatic reduction of cell number was found with the positive control (poly(vinyl chloride) (PVC)). Regarding cells cultured with extracted media, obtained as described previously with BC and BC/PHEMA/PEGDA $(1: 3: 0.05)$ membranes, no significant differences in proliferation rates were observed among them when we compare with negative control; whereas no significant differences exist in growth rate of cells cultured with BC extracted media, a slightly significant lower growth rate was found in the case of cells cultured in BC/PHEMA/PEGDA $(1: 3: 0.05)$ extracted media $(P<0.05)$. However, considering that viability and proliferation rates above $70 \%$ of the control, specifically, $91 \%$ in $\mathrm{BC}$, and $83 \%$ in BC/PHEMA/PEGDA $(1: 3: 0.05)$ membranes were observed here and that according to EN ISO 10993-5:200960 a material is considered cytotoxic if cell viability is reduced by more than 30\%, we can state that $\mathrm{BC}$ and BC/PHEMA/PEGDA $(1: 3: 0.05)$ are not cytotoxic for ADSCs.

With respect to the ADSC seeding assessment, SEM analysis was conducted in order to determine cell morphology, spreading, and adhesion onto BC and BC/PHEMA/PEGDA $(1: 3: 0.05)$ membranes. Figure 11 shows the micrographs of ADSCs taken after $72 \mathrm{~h}$ of seeding on these membranes. In both membranes, ADSCs were well spread, adhered correctly, and proliferated to form a continuous layer of cells fully covering the membranes.

As shown in low magnification photomicrograph (1500x) ADSCs displayed a spindly morphology with numerous cytoplasmic projections firmly attached to material surfaces. In the enlarged images (10000x) the thin cytoplasmic projections adhere actively to the porous network and natural nanofibers structure of the materials. In fact, these nanostructured membranes seem to be ideal for harboring cell growth.

\section{Conclusions}

In the present work, a systematic study for the production of BC/PHEMA nanocomposite films was performed, via in situ radical polymerization of HEMA, using PEGDA as cross-linker, tailoring its properties by the simple ranging of the polymer and/or cross-link content in relation to $\mathrm{BC}$ content, while the $\mathrm{BC}$ nanostructure was retained. The obtained nanocomposite films were fully characterized in terms of composition, transparency, crystallinity, morphology, swelling, thermal and mechanical properties, cytotoxicity, and biocompatibility.

These films are translucent and are considerably more thermally stable than PHEMA matrix. These composites are less rigid materials when compared to $\mathrm{BC}$, which is confirmed by a decrease in the storage tensile modulus, and present good swelling ratios ( 200-260\%). Biocompatibility studies demonstrated that BC/PHEMA nanocomposite films are noncytotoxic providing a favourable cell environment for optimal adhesion and proliferation of ADSCs. Because of this, BC/PHEMA can therefore be seen as a promising material for several biomedical applications, including the design of 3D matrices to maintain a cellular niche for stem cell-mediated tissue regeneration. 


\section{Conflict of Interests}

The authors declare that there is no conflict of interests in the results reported in the present paper.

\section{Acknowledgments}

Andrea G. P. R. Figueiredo and Susana C. M. Fernandes thank the Fundação para a Ciência e Tecnologia (Portugal) for their Scientific Research Grants (SFRH/BPD/63219/2009 and SFRH/BPD/70119/2010, resp.), cofinancing by POPH/ESF Program. The authors thank CICECO (PestC/CTM/LA0011/2013) and FCT for funding within the scope of the "National Program for Scientific reequipment," Rede/ 1509/RME/2005, REEQ/515/CTM/2005, and University of the Basque Country for financial support (UPV/EHU, Project GIU 10/16). The authors also acknowledge the technical and human support of General Research Services (SGIker) from the UPV/EHU for the SEM analysis.

\section{References}

[1] A. Dufresne, "Cellulose-Based Composites and Nanocomposites," in Monomers, Polymers and Composites From Renewable Resources, M. N. Belgacem and A. Gandini, Eds., Elsevier, Amsterdam, Netherlands, 2008.

[2] D. Klemm, B. Heublein, H.-P. Fink, and A. Bohn, "Cellulose: fascinating biopolymer and sustainable raw material," Angewandte Chemie, vol. 44, no. 22, pp. 3358-3393, 2005.

[3] T. Heinze and T. Liebert, "Celluloses and polyoses/hemicelluloses," in Polymer Science, M. Krzysztof and M. Martin, Eds., Elsevier, Amsterdam, Netherlands, 2012.

[4] D. Klemm, F. Kramer, S. Moritz et al., "Nanocelluloses: a new family of nature-based materials," Angewandte Chemie, vol. 50, no. 24, pp. 5438-5466, 2011.

[5] H. P. S. Abdul Khalil, A. H. Bhat, and A. F. Ireana Yusra, "Green composites from sustainable cellulose nanofibrils: a review," Carbohydrate Polymers, vol. 87, no. 2, pp. 963-979, 2012.

[6] L. M. M. Costa, G. M. de Olyveira, P. Basmaji, and L. X. Filho, "Bacterial cellulose towards functional medical materials," Journal of Biomaterials and Tissue Engineering, vol. 2, no. 3, pp. 185196, 2012.

[7] R. J. B. Pinto, M. C. Neves, C. P. Neto, and T. Trindade, "Composites of cellulose and metal nanoparticles," in Nanocomposites-New Trends and Developments, F. Ebrahimi, Ed., InTech, Rijeka, Croatia, 2012.

[8] P. Carreira, J. A. S. Mendes, E. Trovatti et al., "Utilization of residues from agro-forest industries in the production of high value bacterial cellulose," Bioresource Technology, vol. 102, no. 15, pp. 7354-7360, 2011.

[9] E. Trovatti, L. S. Serafim, C. S. R. Freire, A. J. D. Silvestre, and C. P. Neto, "Gluconacetobacter sacchari: an efficient bacterial cellulose cell-factory," Carbohydrate Polymers, vol. 86, no. 3, pp. 1417-1420, 2011.

[10] L. Fu, J. Zhang, and G. Yang, "Present status and applications of bacterial cellulose-based materials for skin tissue repair," Carbohydrate Polymers, vol. 92, no. 2, pp. 1432-1442, 2013.

[11] L. M. M. Costa, G. M. de Olyveira, B. M. Cherian, A. L. Leão, S. F. de Souza, and M. Ferreira, "Bionanocomposites from electrospun PVA/pineapple nanofibers/Stryphnodendron adstringens bark extract for medical applications," Industrial Crops and Products, vol. 41, no. 1, pp. 198-202, 2013.

[12] L. M. M. Costa, G. M. Olyveira, P. Basmaji et al., "Novel otoliths/bacterial cellulose nanocomposites as a potential natural product for direct dental pulp capping," Journal of Biomaterials and Tissue Engineering, vol. 2, no. 1, pp. 48-53, 2012.

[13] E. Trovatti, C. S. R. Freire, P. C. Pinto et al., "Bacterial cellulose membranes applied in topical and transdermal delivery of lidocaine hydrochloride and ibuprofen: in vitro diffusion studies," International Journal of Pharmaceutics, vol. 435, no. 1, pp. 8387, 2012.

[14] J. L. Lopes, J. M. Machado, L. Castanheira et al., "Friction and wear behaviour of bacterial cellulose against articular cartilage," Wear, vol. 271, no. 9-10, pp. 2328-2333, 2011.

[15] R. J. B. Pinto, P. A. A. P. Marques, C. P. Neto, T. Trindade, S. Daina, and P. Sadocco, "Antibacterial activity of nanocomposites of silver and bacterial or vegetable cellulosic fibers," Acta Biomaterialia, vol. 5, no. 6, pp. 2279-2289, 2009.

[16] R. Hobzova, M. Duskova-Smrckova, J. Michalek, E. Karpushkin, and P. Gatenholm, "Methacrylate hydrogels reinforced with bacterial cellulose," Polymer International, vol. 61, no. 7, pp. 1193-1201, 2012.

[17] Y. Feng, X. Zhang, Y. Shen, K. Yoshino, and W. Feng, "A mechanically strong, flexible and conductive film based on bacterial cellulose/graphene nanocomposite," Carbohydrate Polymers, vol. 87, no. 1, pp. 644-649, 2012.

[18] G. F. Perotti, H. S. Barud, Y. Messaddeq, S. J. L. Ribeiro, and V. R. L. Constantino, "Bacterial cellulose-laponite clay nanocomposites," Polymer, vol. 52, no. 1, pp. 157-163, 2011.

[19] J. Shah and R. M. Brown Jr., "Towards electronic paper displays made from microbial cellulose," Applied Microbiology and Biotechnology, vol. 66, no. 4, pp. 352-355, 2005.

[20] H. S. Barud, J. M. A. Caiut, J. Dexpert-Ghys, Y. Messaddeq, and S. J. L. Ribeiro, "Transparent bacterial cellulose-boehmiteepoxi-siloxane nanocomposites," Composites A, vol. 43, no. 6, pp. 973-977, 2012.

[21] J. M. A. Caiut, H. D. S. Barud, Y. Messaddeq, and S. J. L. Ribeiro, "Optically transparent composites based on bacterial cellulose and boehmite, siloxane and/or a boehmite-siloxane system," Patent WO/2012/100315, 2012.

[22] E. Trovatti, L. Oliveira, C. S. R. Freire et al., "Novel bacterial cellulose-acrylic resin nanocomposites," Composites Science and Technology, vol. 70, no. 7, pp. 1148-1153, 2010.

[23] S. Gea, E. Bilotti, C. T. Reynolds, N. Soykeabkeaw, and T. Peijs, "Bacterial cellulose-poly(vinyl alcohol) nanocomposites prepared by an in-situ process," Materials Letters, vol. 64, no. 8, pp. 901-904, 2010.

[24] I. M. G. Martins, S. P. Magina, L. Oliveira et al., "New biocomposites based on thermoplastic starch and bacterial cellulose," Composites Science and Technology, vol. 69, no. 13, pp. 21632168, 2009.

[25] S. C. M. Fernandes, L. Oliveira, C. S. R. Freire et al., "Novel transparent nanocomposite films based on chitosan and bacterial cellulose," Green Chemistry, vol. 11, no. 12, pp. 2023-2029, 2009.

[26] S. C. M. Fernandes, C. S. R. Freire, A. J. D. Silvestre et al., "Transparent chitosan films reinforced with a high content of nanofibrillated cellulose," Carbohydrate Polymers, vol. 81, no. 2, pp. 394-401, 2010.

[27] E. Trovatti, S. C. M. Fernandes, L. Rubatat, C. S. R. Freire, A. J. D. Silvestre, and C. P. Neto, "Sustainable nanocomposite films 
based on bacterial cellulose and pullulan," Cellulose, vol. 19, no. 3, pp. 729-737, 2012.

[28] A. L. Buyanov, I. V. Gofman, L. G. Revel'skaya, A. K. Khripunov, and A. A. Tkachenko, "Anisotropic swelling and mechanical behavior of composite bacterial cellulose-poly(acrylamide or acrylamide-sodium acrylate) hydrogels," Journal of the Mechanical Behavior of Biomedical Materials, vol. 3, no. 1, pp. 102-111, 2010.

[29] N. Halib, M. C. I. M. Amin, and I. Ahmad, "Unique stimuli responsive characteristics of electron beam synthesized bacterial cellulose/acrylic acid composite," Journal of Applied Polymer Science, vol. 116, no. 5, pp. 2920-2929, 2010.

[30] J. Zhang, J. Rong, W. Li, Z. Lin, and X. Zhang, "Preparation and characterization of bacterial cellulose/polyacrylamide hydrogel," Acta Polymerica Sinica, no. 6, pp. 602-607, 2011.

[31] F. Kramer, D. Klemm, D. Schumann et al., "Nanocellulose polymer composites as innovative pool for (Bio)material development," Macromolecular Symposia, vol. 244, pp. 136-148, 2006.

[32] M. C. I. Mohd Amin, N. Ahmad, N. Halib, and I. Ahmad, "Synthesis and characterization of thermo- and $\mathrm{pH}$-responsive bacterial cellulose/acrylic acid hydrogels for drug delivery," Carbohydrate Polymers, vol. 88, no. 2, pp. 465-473, 2012.

[33] J. Kopeĉek, "Hydrogels: from soft contact lenses and implants to self-assembled nanomaterials," Journal of Polymer Science A, vol. 47, no. 22, pp. 5929-5946, 2009.

[34] T. V. Chirila, "An overview of the development of artificial corneas with porous skirts and the use of PHEMA for such an application," Biomaterials, vol. 22, no. 24, pp. 3311-3317, 2001.

[35] S. Atzet, S. Curtin, P. Trinh, S. Bryant, and B. Ratner, "Degradable poly(2-hydroxyethyl methacrylate)-co-polycaprolactone hydrogels for tissue engineering scaffolds," Biomacromolecules, vol. 9, no. 12, pp. 3370-3377, 2008.

[36] D. Horák, H. Hlídková, J. Hradil, M. Lapčíková, and M. Šlouf, "Superporous poly(2-hydroxyethyl methacrylate) based scaffolds: preparation and characterization," Polymer, vol. 49, no. 8, pp. 2046-2054, 2008.

[37] S. Hestrin and M. Schramm, "Synthesis of cellulose by Acetobacter xylinum-II. Preparation of freeze-dried cells capable of polymerizing glucose to cellulose," The Biochemical Journal, vol. 58, no. 2, pp. 345-352, 1954.

[38] S. C. M. Fernandes, P. Sadocco, A. Alonso-Varona et al., "Bioinspired antimicrobial and biocompatible bacterial cellulose membranes obtained by surface functionalization with aminoalkyl groups," ACS Applied Materials \& Interfaces, vol. 5, no. 8, pp. 3290-3297, 2013.

[39] D. Gulsen and A. Chauhan, "Effect of water content on transparency, swelling, lidocaine diffusion in p-HEMA gels," Journal of Membrane Science, vol. 269, no. 1-2, pp. 35-48, 2006.

[40] D. N. S. Hon, Chemical Modification of Lignocellulosic Materials, Marcel Dekker, New York, NY, USA, 1996.

[41] D. Klemm, Comprehensive Cellulose Chemistry: Fundamentals and Analytical Methods, Wiley-VCH, 1998.

[42] N. Nishioka, T. Itoh, and M. Uno, “Thermal decomposition of cellulose/synthetic polymer blends containing grafted products. IV. Cellulose/poly(2-hydroxyethyl methacrylate) blends," Polymer Journal, vol. 31, no. 12, pp. 1218-1223, 1999.

[43] R. K. Bose and K. K. S. Lau, "Mechanical properties of ultrahigh molecular weight PHEMA hydrogels synthesized using initiated chemical vapor deposition," Biomacromolecules, vol. 11, no. 8, pp. 2116-2122, 2010.
[44] R. Pértile, S. Moreira, F. Andrade, L. Domingues, and M. Gama, "Bacterial cellulose modified using recombinant proteins to improve neuronal and mesenchymal cell adhesion," Biotechnology Progress, vol. 28, no. 2, pp. 526-532, 2012.

[45] M. E. Gomes, T. Rada, and R. L. Reis, "Adipose tissue-derived stem cells and their application in bone and cartilage tissue engineering," Tissue Engineering B, vol. 15, no. 2, pp. 113-125, 2009.

[46] A. Sterodimas, J. De Faria, B. Nicaretta, and I. Pitanguy, “Tissue engineering with adipose-derived stem cells (ADSCs): current and future applications," Journal of Plastic, Reconstructive and Aesthetic Surgery, vol. 63, no. 11, pp. 1886-1892, 2010. 

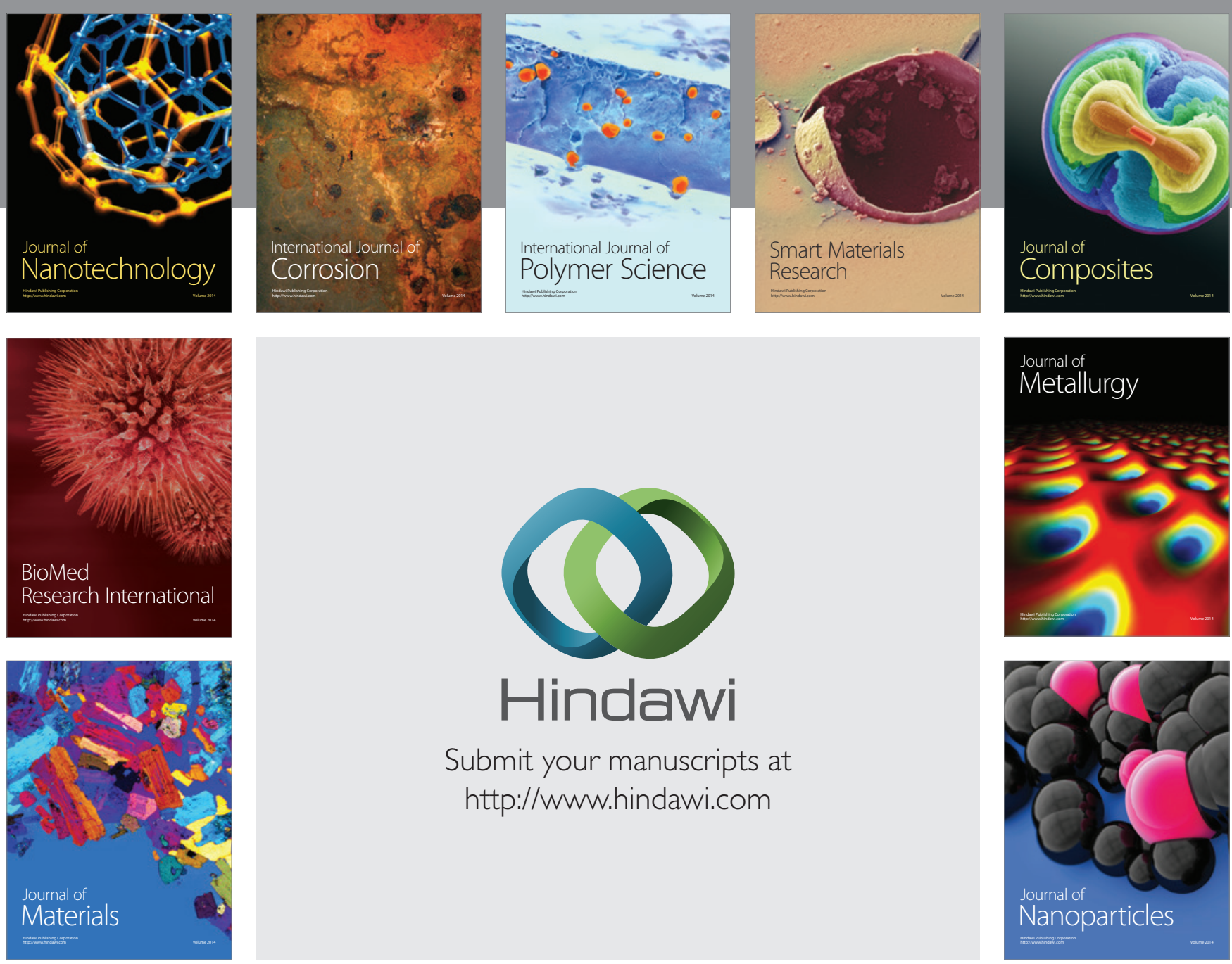

Submit your manuscripts at http://www.hindawi.com
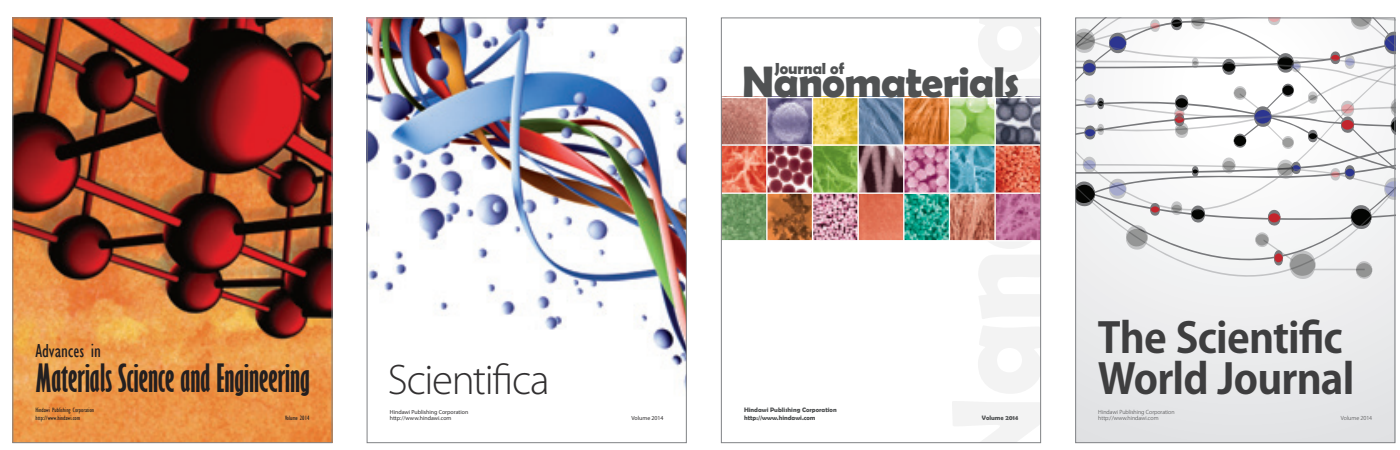

\section{The Scientific World Journal}
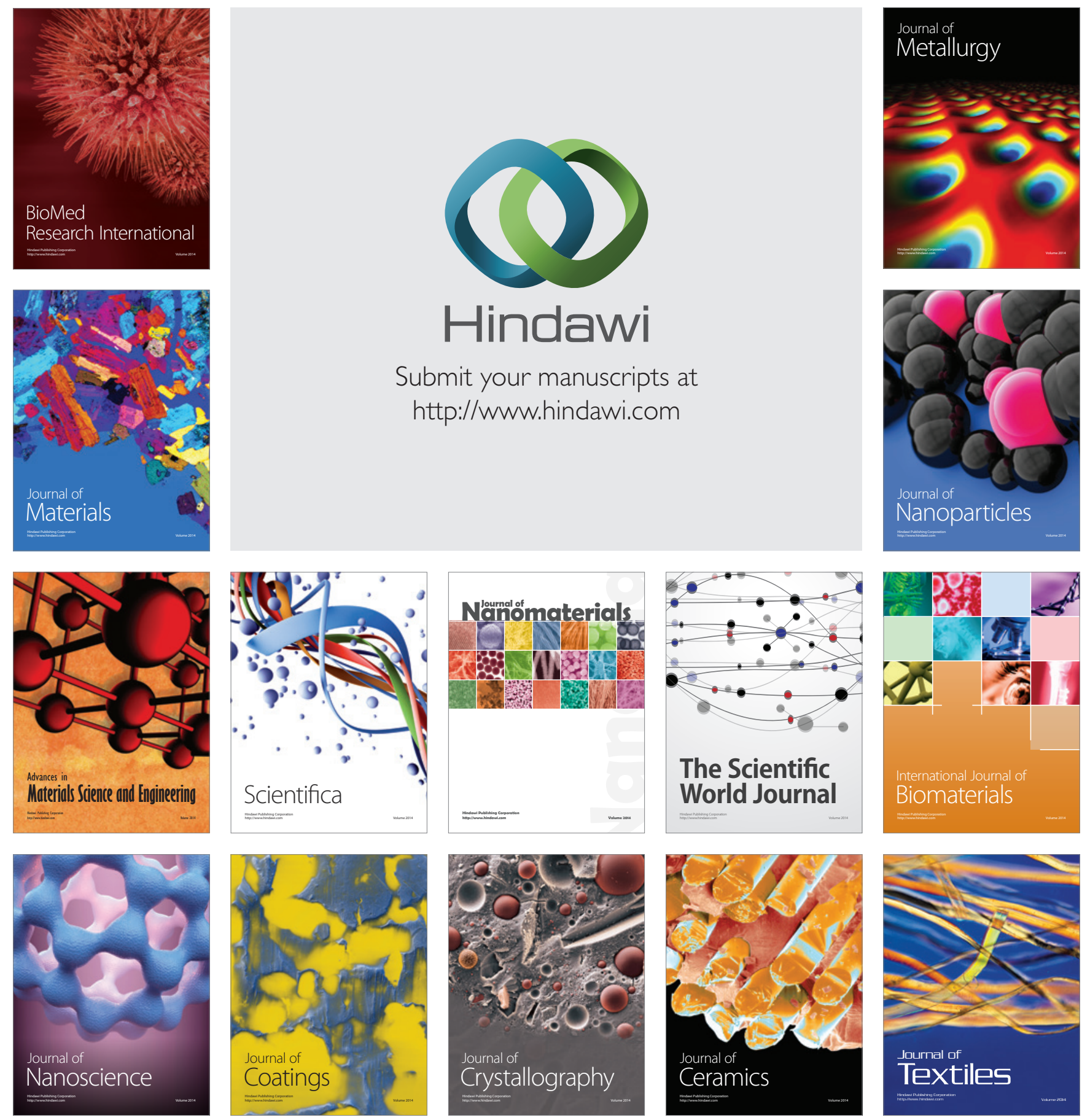